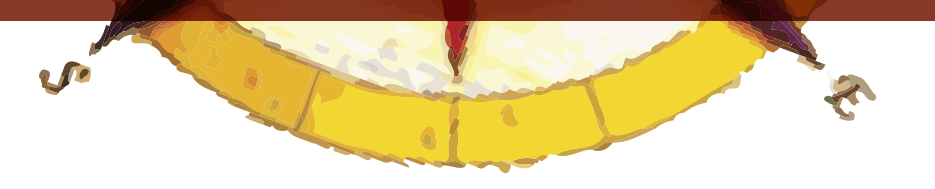

\title{
TERMINOLOGÍAS IMPLÍCITAS EN EL PROCESO DE DESARROLLO PROFESIONAL DOCENTE
}

\author{
Tania Briceño Román ${ }^{30}$ \\ Verónica Salgado L. ${ }^{31}$
}

\section{RESUMEN}

E1 siguiente texto constituye una reflexión en torno al concepto de desarrollo profesional docente y a una serie de términos asociados a éste.

La importancia de discutir en torno a estos conceptos no radica solamente en la posibilidad de entender su significado, sino que además pretende ingresar en el reconocimiento de las concepciones que sustentan la manera en que son entendidos.

De esta forma, el presente documento, avanza desde la presentación de significados hacia la discusión sobre la significancia que presentan estos procesos -situados como conceptualizacionespara el mundo educativo y específicamente para la comprensión del rol y accionar docente en dicho contexto.

Palabras Claves: formación docente, maestro reflexivo.

\section{RESUMO}

O texto a seguir é uma reflexão sobre o conceito de desenvolvimento profissional docente e um número de termos associados.

A importância de discutir sobre esses conceitos não é apenas na capacidade de compreender o seu significado, mas também a tentar entrar no reconhecimento dos conceitos subjacentes à forma como eles são compreendidos.

Assim, este artigo procede a partir da apresentação de significados para a discussão da importância que esses processos ocorrem posicionada como conceituações, para o mundo educacional e especificamente para a compreensão do papel e atuação dos professores neste contexto.

Palavras Chaves: Formação docente, professor reflexivo.

30 Profesora de Historia y Ciencias Sociales, Universidad Academia de Humanismo Cristiano.

31 Profesora de Historia y Ciencias Sociales, Candidata a Magíster por la Universidad de São Paulo. 


\begin{abstract}
The following article is a reflection on the concept of teacher's professional development and a number of associated terms. The importance of discussing these concepts is not only the ability to understand its meaning, but also trying to get the recognition of the underlying concepts of how they are understood.
\end{abstract}

Thus, this article proceeds from the production of meanings for the discussion of the importance that these processes occur positioned as concepts for the educational world and specifically for understanding the role and activities of teachers in this context.

Keywords: Teacher education, reflective teacher.

\title{
INTRODUCCIÓN
}

El siguiente texto constituye una reflexión en torno al concepto de desarrollo profesional docente y a una serie de términos asociados a éste. La importancia de discutir sobre estos conceptos no radica solamente en la posibilidad de entender su significado, sino que además pretende ingresar en el reconocimiento de las concepciones que sustentan la manera en que son entendidos.

De esta forma, el presente documento, avanza desde la presentación de significados hacia la discusión sobre la significancia que presentan estos procesos -situados como conceptualizacionespara el mundo educativo y específicamente para la comprensión del rol y accionar docente en dicho contexto.

Así, se pone de manifiesto lo importante que resulta visualizar las concepciones desde las que pueden entenderse los distintos procesos de formación docente y su rol como profesional de la educación, a fin de contribuir a la toma de decisiones sobre los aspectos que son necesarios reforzar a lo largo de su formación.

La incorporación de los temas que aquí se pretende poner en discusión resultan ser centrales sobre todo para los propios docentes, ya que invita a repensar importantes aspectos involucrados en el ámbito de la formación profesional entendiendo ésta como un continuo en el quehacer docente.

\section{DESARROLLO PROFESIONAL DEL DOCENTE}

Numerosa es la literatura disponible en el mundo sobre la profesión docente, esto debido a que se trata de una profesión compleja, que puede ser abordada desde distintos enfoques o miradas, y concebida bajo distintos fundamentos epistemológicos. Lo cierto es que desde hace algunos años, se han ido generando debates con respecto a este tema, pues, cada vez con mayor auge, se ha tomando en consideración que el desarrollo de la profesionalidad de los docentes, posee una gran importancia e incidencia en distintos ámbitos y dimensiones educativas que hoy en día se discuten tanto en las esferas políticas, académicas, como en la sociedad en general, y es que, el desarrollo profesional estaría en directa consonancia con la calidad de la educación.

Esto quiere decir, que la capacidad de mejorar la profesionalidad de los docentes en ejercicio -que 
implica una responsabilidad implícita tanto en los procesos de formación inicial como también de la formación continua- está en directa relación con las posibilidades de mejora en la calidad de la educación, y aunque, la labor docente no sea la única arista a considerar en una revisión sobre la calidad educativa, ciertamente es un área central y de enorme influencia para alcanzarla.

En este contexto, es posible mencionar que existen distintos conceptos que nos invitan a reflexionar sobre la profesionalización docente, no obstante, hemos de ser cuidadosos y precavidos en sus usos, ya que muchas veces se tiende a utilizar indistintamente conceptos que son confusos y un tanto ambiguos para referirse al tema. Podemos nombrar por ejemplo los términos profesión, profesionalización, profesionalismo ó profesionalidad, los que, si bien, pueden parecer sinónimos debido a que se asocian a una misma idea, lo cierto es que lo hacen desde distintas perspectivas, abarcando distintas esferas, y por tanto generando un nivel de incidencia desigual.

Imbernón (1999) nos explica que cada uno de los términos expuestos en el párrafo anterior, posee un alto grado de complejidad en sus significados y definiciones, ya que, se trata de construcciones teóricas que han ido evolucionando a lo largo del tiempo, y por tanto, no resulta fácil aprehenderlos, sobretodo considerando los distintos contextos sociales y educativos existentes en las sociedades. Para el autor, esta situación se complejiza aún más al considerar, a la docencia, como una actividad de carácter social

...en donde las características de los individuos, del contexto en que se ejerce la profesión, y la diversidad de actividades específicas laborales que han de asumir son de una gran variedad y por tanto no pueden encontrarse los límites entre donde empieza lo profesional y lo no profesional desde un punto de vista de búsqueda de unas características o cualidades comunes a toda la profesión. (p.16)

De este modo, el autor nos explica, a partir de la revisión de las definiciones, cuál es la pertinencia de cada uno de los términos. Para el caso del término profesión, el autor expone que siempre se refiere a las condiciones sociolaborales de un profesional, no obstante, posee significados diversos dependiendo de la actividad laboral o la labor profesional a la que se refiera, y que además, según las estructuras sociales y el contexto específico en el que se esté instalado, recobrará un sentido particular.

Una vez aclarado el término profesión, el mismo autor define el concepto profesionalización, que será entendido como

....un proceso de socialización profesional constante tanto en la preparación inicial para una ocupación definida, como en un proceso continuo de búsqueda y perfeccionamiento personal y laboral en el que intervienen varios elementos comunes de la ocupación laboral y que se vincula a una determinada práctica profesional. (p.14)

En relación a esto, el autor advierte que existen distintos estadios o etapas de profesionalización, ya que, por una parte podemos encontrar la presencia de este proceso en la formación inicial de un profesional, como también a lo largo de toda una vida profesional. En este sentido, profesionalización y desarrollo profesional serían conceptos que podrían utilizarse como sinónimos.

Ahora bien, en el caso particular de la profesión docente, tanto en la literatura, como en los estudios e investigaciones que se han construido en torno al tema, se suele nombrar insistentemente los términos profesionalismo o profesionalidad, conceptos utilizados para referirse a un mismo proceso. 
En relación a los conceptos mencionados, puede decirse que existe una relación entre profesionalismo y profesionalización, ya que en el proceso de profesionalismo, se da cuenta necesariamente de procesos que instalan al docente a vivenciar la acción de formación profesional, como también se insta a éstos a experienciar distintas actividades de desarrollo profesional

En términos generales, siempre la profesionalidad implica una referencia a unas determinadas características específicas (cuerpo teórico, dominio de determinadas destrezas, habilidades profesionales, decisiones profesionales), debidas a la formación y a la experiencia de la persona que ejerce la actividad laboral, que se aplica a una determinada forma asumida por la organización de trabajo y que está expuesta a la dinámica externa del mercado del trabajo; por tanto ser un profesional, implica pasar por un proceso de profesionalización y tener una profesionalidad para dominar una serie de capacidades y habilidades especializadas que hacen ser competente en un determinado trabajo, que va más allá de una simple ocupación y permiten entrar en la dinámica del mercado laboral y que, además une a un grupo profesional más o menos coordinado (maestros, maestras, o profesores y profesoras) y sujeto a algún tipo de control interno o externo. (Imbernón, 1999, p.15)

Por su parte, Perrenoud, Paquay, Altet y Charlier, (2008) definen algunas características que un profesor profesional debiera poseer, como aquel que aprende a ser una persona autónoma, que ha desarrollado competencias específicas y especializadas que reposan sobre una base de conocimiento racional, conocimiento que tiene su origen en la ciencia, que es legitimado en la academia, y que además, se complementa con otro tipo de conocimiento, el que se desarrolla y fortalece con la práctica pedagógica. Así mismo, los autores, definen que la profesionalización es constituida por un proceso de racionalización de conocimientos puestos en acción a través de prácticas eficaces dentro de un contexto específico o en una determinada situación. Con esto, se asume que los docentes profesionales saben accionar sus competencias en cualquier situación, de hecho, los autores denominan a los docentes profesionales, como "hombres de situación", los que siempre son capaces de adaptarse y de dominar cualquier nueva situación, por más desconocida que ésta sea

...es un profesional admirado por su capacidad de adaptación, su eficacia, su experiencia, su capacidad de respuesta y de ajuste a cada demanda, al contexto o a los problemas complejos y variados, también por su capacidad de relatar sus conocimientos, su saber- hacer, y sus actos. (p.25)

En efecto, éstas serían las principales características que debería tener un profesional de la educación, configurándose con ello, los fundamentos del modelo de profesionalismo que los autores proponen. Así mismo, y con la finalidad de reforzar aún más su propuesta, desarrollan un breve bosquejo de cuáles han sido las características que han constituido los modelos de profesionales docentes que históricamente se han utilizado.

Según esto, podemos encontrar en primer lugar, el Profesor Maestro, que se relaciona con el maestro de la antigüedad, que sabe que no necesita una formación específica, pues su carisma, y sus competencias retóricas son suficientes. Otro modelo, corresponde al Profesor Técnico, que surge en las escuelas normales, cuya formación y oficio, ocurre por aprendizaje e imitación con apoyo de la práctica. En éste tipo de docente, son los trucos y las técnicas las que destacan por excelencia. Contrario a este modelo, encontramos el Profesor Ingeniero o Tecnólogo, que se apoya en los aportes científicos trabajados por las ciencias humanas, de manera que procura aplicar la teoría en función de su práctica. Por último, los autores proponen como cuarto modelo el del Profesor Profesional o Reflexivo

...en este cuarto modelo, la dialéctica entre teoría y práctica es sustituida por un ir y venir entre PRÁCTICA- TEORÍA- PRÁCTICA, el profesional se torna un profesional reflexivo, capaz de anali- 
zar sus propias prácticas, de resolver problemas, de inventar estrategias; la formación se apoya en las contribuciones de practicantes y de, en vista de desenvolver al profesor a un abordaje de situaciones vividas de tipo ACCIÓN- CONOCIMIENTO- PROBLEMA, utilizando conjuntamente práctica y teoría para construir en el profesor capacidades de análisis de sus prácticas y de su metacognición (p.26)

Es en este sentido, que la propuesta generada por los autores mencionados radica en la consideración de un profesor profesional que es, ante todo, un especialista del proceso de enseñanza aprendizaje, un profesional capaz de hacer interactuar distintas significaciones parceladas en distintos contextos.

Charlier (2008) especifica aún más estas características, nombrando las siguientes:

- Lleva en cuenta de manera deliberada el mayor número de parámetros posibles de situación de formación considerada.

- Se articula de manera crítica (con ayuda de teorías personales o colectivas).

- Considera una o varias posibilidades de conductas y toma de decisiones de planeamiento de su acción.

- Ajusta su acción de inmediato si percibe que esto es necesario (reflexión en acción).

- Saca lecciones de su práctica para más tarde (reflexión sobre la acción).

En este sentido, la autora enfatiza la adaptabilidad del docente profesional, como una posibilidad de acción en distintas situaciones, y como una capacidad de enfrentar los cambios en el ejercicio de su labor. Luego de estas definiciones, es posible afirmar, retomando a Imbernón, que no existe total consenso con respecto a la definición del concepto profesión.

De esta manera, existen concepciones que arraigadas en el tradicionalismo, consideran el concepto de profesión como el quehacer de un profesional que desarrolla su accionar basado en una formación inicial que entrega un conocimiento inmutable en el tiempo. Así, el profesional adquiere un conocimiento verdadero, estable y estático que no es necesario actualizar ni reformular en función de los cambios y los contextos donde se desenvuelva.

En un extremo diferente, emergen postulados cuyo punto de partida es el entendimiento de que la profesión envuelve a la profesionalización. Por ende, la profesión es un proceso dinámico, en constante movimiento, y flexible a los cambios laborales y sociales, junto con ser variable en función del contexto en el que se desarrolle. Concepciones que establecen coherencia con el modelo de profesionales reflexivos comentado con anterioridad.

La influencia de estas concepciones, invita a reflexionar sobre la importancia de considerar la profesionalización docente como un proceso en constante construcción, que implica la permanente reflexión sobre su práctica, en función de las necesidades que el contexto de trabajo proponga.

Bajo este análisis resulta prudente desarrollar los siguientes cuestionamientos, ¿Qué significa ser un profesional de la educación?, ¿Qué es ser un docente profesional, ¿Cómo éstos deben actuar?. Estamos frente a preguntas igualmente difíciles de responder. Autores que se han formulado éstas 
y otros interrogantes con respecto a la formación profesional de los docentes, disponen de una lista resumida de competencias que un profesional docente debiera cumplir, entre las que podemos destacar.

- Analizar situaciones complejas, tomando como referencia diversas formas de lectura;

- Optar de manera rápida y reflexiva por estrategias adaptadas a los objetivos y exigencias éticas;

- Escoger entre una amplia gama de conocimientos, técnicas e instrumentos, los medios más adecuados que estructuran la forma de un dispositivo;

- Adaptar rápidamente sus proyectos en función de la experiencia;

- Analizar de manera crítica sus acciones y sus resultados;

- En fin, aprender por medio de esa validación continua, a lo largo de toda su carrera. (Perrenoud, 2008, p.12)

Según esto, la labor del docente y el profesionalismo del profesor, no se reduce al dominio de conocimientos profesionales diversos, más bien, se amplía, al deber incorporar esquemas de percepción, de análisis, de decisión, de planeamiento, entre otros. En este sentido, los autores antes mencionados, definirán las "competencias profesionales" del docente como:

Un conjunto diversificado de conocimientos de la profesión, de esquemas de acción y de posturas que son movilizadas en el ejercicio del oficio. De acuerdo con esta definición bien amplia, las competencias son al mismo tiempo, de orden cognitiva, afectiva, y práctica. (Perrenoud, 2008, p.12)

Por tanto, al afirmar que las acciones y las posturas son "movilizadas" en el ejercicio del oficio, estamos nuevamente dando cuenta del carácter flexible y de la constante construcción que es en sí misma la profesionalización docente.

No obstante, es necesario advertir que, si bien la formación es parte del desarrollo profesional del profesorado, no todo desarrollo profesional, forma parte de la formación. Además, como hemos mencionado más arriba, el desarrollo profesional varía producto de diversos factores, entre ellos podemos nombrar, la calidad de la formación inicial, el salario, y el contexto de trabajo.

Otro autor que reafirma las ideas comentadas es Tardif (2004) quien propone una definición para el docente profesional señalando que,

Un docente profesional no es sólo una persona que aplica conocimientos producidos por otros, no es sólo un agente determinado por mecanismos sociales: es un actor en el sentido fuerte de la palabra, es decir, un sujeto que asume su práctica a partir de los significados que él mismo le da, un sujeto que posee conocimientos y un saber hacer proveniente de su propia subjetividad y a partir de los cuales la estructura y las orienta. (Tardif, 2004, p.169)

En este sentido, sería necesario que los docentes no se adormezcan, y que por el contrario, sean partícipes de una continua revisión, reconstrucción y autocrítica de su accionar. En las siguientes líneas, Barraza, Casanova y García Ugarte (2007), nos invitan a reflexionar y asumir que 
...no es posible entender (si no es desde la absoluta contradicción) ser educador y no estar abierto al cambio...la opción por el inmovilismo y el poder de la costumbre responde más a quien educa desde el miedo, que a quien afronta el apasionante reto de conocer la realidad que cambia. Nuestros alumnos (sus ideas, valores, modos de entender y vivir la vida) no son los mismos que teníamos hace diez años, y tendrán muy poco que ver con los de la próxima década. (p.95)

De este modo, la autora corrobora la idea de que la capacidad de acomodación y constante reconversión al cambio que deben tener los profesionales docentes, cobra cada vez mayor importancia y relevancia, en el contexto de un mundo conformado por una multitud de cambios sociales, educativos, políticos, económicos, etc., los que debieran a su vez producir movimientos tanto en el pensar, como en el accionar de los docentes.

\section{IDEAS FINALES}

Probablemente a algunos lectores pueda parecer rebuscada la aclaración de conceptos tan parecidos y que en la cotidianeidad son usados como sinónimos, sin embargo, la reflexión en torno a los conceptos que rodean el término profesión, contextualizado en el quehacer docente, no sólo invita a una diferenciación terminológica por el afán de nombrar un proceso u otro, sino que resulta relevante porque permite percibir que las distinciones en sus usos implica un abanico de creencias y concepciones sobre el rol del docente y sobre la responsabilidad que implica el involucramiento con un proceso educativo.

La convicción de entender al docente como un profesional reflexivo en constante formación, implica incorporar nuevas exigencias a su quehacer sobretodo en el ámbito cognitivo y de cuestionamiento a las concepciones con las que se enfrenta el proceso educativo, así mismo logra transgredir concepciones que se basan en paradigmas basados en la creencia de una verdad absoluta y que imposibilitan la aplicación y generación de reformulamientos y transformaciones en el ámbito del conocimiento y en el de las acciones.

Por otro lado, la ampliación de la profesión docente hacia una mirada que visualiza al profesional como un sujeto en constante formación, da la oportunidad de que los docentes se vuelvan profesionales críticos y cuestionadores de sus prácticas, acción que es esencial para el mejoramiento de éstas. Junto con ello, permite que tomen suya la responsabilidad de suplir carencias que puedan haber permanecido luego de la formación inicial y se integren a procesos de formación constante.

De ahí se desprende también, la convicción de que los cambios a nivel temporal, generacional, como también contextuales, son una oportunidad y al mismo tiempo una exigencia para repensar las competencias profesionales que se tienen y perfeccionarlas.

\section{BIBLIOGRAFÍA}

Barraza, L. y otros. (2007). Ser profesor y dirigir profesores en tiempos de cambio. Ediciones Nancea, Madrid.

Charlier, E. y otros (2008) Formando Professores Profissionais. Quais estratégias? Quais competencias? Artmed, Porto alegre. 
Imbernón, F. y otros (1999). Formación y actualización para la función pedagógica. Editorial Síntesis Educación, Madrid.

Perrenoud, P. y otros. (2008). Formando profesores profissionais, quais estratégias? Quais competencias? Editorial Artmed, Sao Paulo.

Tardif, M. (2004). Los saberes del docente y su desarrollo profesional. Narcea Ediciones, Madrid. Artículo recibido 20 - 09 - 11. Aprobado $25-11-11$. 